\section{Super Proton Synchroton project}

Europe's Giant Accelerator: The Story of the CERN $400 \mathrm{GeV}$ Super Proton Synchrotron. By Maurice Goldsmith and Edwin Shaw. Pp. 288. (Taylor and Francis: London, 1977.) $£ 13$.

IN telling the tale of the Super Proton Synchrotron (SPS) project, Maurice Goldsmith and Edwin Shaw have produced a book that is both fascinating and frustrating. Although it is explicitly stated that the views and comments presented are those of the authors and not the official opinion of the European Organisation for Nuclear Research (CERN), the authors do not often stray from the party line, and the text tends to glorify CERN and praise the success of the SPS. And why notit is a story to be proud of.

Beginning with a brief and rather high-minded justification for high energy accelerators the authors move straight into the political wranglings that continued for so many years before the SPS project was accepted and funded. A detailed description of the birth-throes is given but its conception is handled more discretely. It will be difficult for an uncommitted reader to become emotionally involved as the political and scientific justification for the SPS is inadequately presented. The reader needs to be emotionally involved to appreciate the detailed description of the implementation of the project which is presented in the rest of the book.

The discussion of the fight for acceptance of the SPS project is fascinating. The brevity of the discussion is frustrating. After rather fullsome praise of the CERN convention - the rules by which CERN operatesit comes as a shock that it did not seem to work too well in the case of the SPS. More comment on this would have been welcome, as would be additional discussion of the roles of the various member states during the negotiations. One gets the impression that only a small part of the story has been told-enough to whet the appetite but insufficient to give full satisfaction.

Turning to the building of the machine itself, the authors describe the process in great detail in separate chapters dealing with individual aspects of the problem: surveying, magnets, power and water supplies, radiofrequency acceleration, and so ontopics beloved by engineers and belittled by everyone else, but presented here in an exciting style. Aspects often taken for granted are revealed as complex technical problems and their solution is surprisingly interesting, not least because of the clear way in which they are presented.

Apt portraits are given of most of the key personnel in the project-a device which adds a great deal of interest to the technological descriptions but, even so, in places far too much technical detail is included and the story becomes difficult to follow. In general, however, there is a good blend of personal interest, technical detail, explanation and discussion of management techniques, which makes a very readable story.

Although the text is fascinating, the layout of the book is frustrating. Pictures are liberally sprinkled throughout; most are of interest but others are fatuous, and the text is fitted into the remaining space after huge margins have been accommodated. If a picture

\section{Organic reaction mechanisms}

Reaction Mechanisms in Organic Chemistry. By Florin Badea. Pp. 701. (Abacus: Tunbridge Wells, Kent, UK, 1977.) £18.85.

THE investigation of organic reaction mechanisms by the application of kinetic measurements originated with Lapworth's work on the halogenation of acetone, at the beginning of the present century. It was not until much later, after 1930, and especially through Ingold's work on substitution reactions, that mechanistic studies became accepted as the cornerstone of the scientific basis of modern organic chemistry. Almost any recent textbook of organic chemistry, even at an elementary level, reflects this view. Several more specialised treatises, including the famous ones by Ingold and Hammett, have given more detailed analyses of the problems of reaction mechanisms in relation to the structure of organic compounds. The work now under review is a recent addition to the literature in the second category. Its author is Professor of Organic Chemistry at the Polytechnical Institute, Bucharest, Romania, and we learn that his research experience included a period in Donald Cram's laboratory at UCLA. The book is well translated (by the author, with help) into readable, though not altogether faultless, English.

The text starts with an introduction to group theory, an account of the Hückel molecular orbital (HMO) method, some rudimentary thermodynamics and statistical mechanics, a statement of the principles of chemical kinetics, and a brief survey of reaction intermediates. These sections are is encountered, on turning a page one has to search frantically for the text; often there isn't any. Even when there are no pictures the text does not begin until nearly a quarter of the way down the page.

It would have been preferable to expand the scope of the book to put the SPS project into context and explain more fully the motivations and use to which it will be put. This could have been done without increase of the (already high) cost, at the expense of reducing the space taken up by pictures.

This book is one which can usefully be read even though it is produced as if it were a glossy handout for a publicity department. Stuart Sharrock

Stuart Sharrock is Physical Sciences Editor of Nature.

followed by a detailed treatment of mechanisms of a large number of selected reactions, beginning with aliphatic substitution and ending with cycloadditions. The level of the treatment is intended for postgraduates and advanced undergraduates.

In its 700 crowded pages the book manages to include a vast amount of material and many references. Much of the information is of recent date, and it is not surprising that frequently the aptness of its selection is at least debatable. Clearly, in such an enormous undertaking, there are also bound to be errors of fact or interpretation. Some of these are excusable and could prove a challenge to a good student. The author does not generally attempt unconventional interpretations or to resolve conflicting views. He is not afraid to show his limitations and to leave the reader to develop his own critical faculty by sifting the arguments presented.

Probably the least satisfactory aspect of the book is the absence of any coherent attempt to explain the current methodology of the elucidation of reaction mechanisms. This is not a text from which a student could gain a satisfactory understanding of the application of kinetic methods and become aware of its pitfalls, for example. The treatment of topics such as the role of pre-equilibria, the stationary-state hypothesis, kinetic salt effects, or kinetic isotope effects is inadequate and sometimes seriously in error.

Nevertheless, the book is quite good in parts but, as better introductions to the subject are available in the English language, it is unlikely to be widely adopted.

V. Gold

V. Gold is Professor of Chemistry at King's College, University of London, UK. 